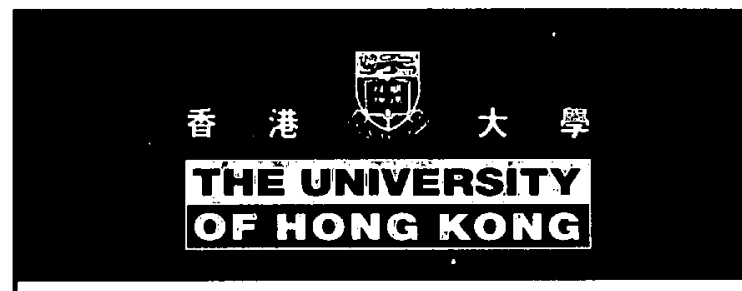

As the most established tertiary education institution in Hong Kong, the University of Hong Kong has attained unparalleled achievements since 1911 in Hong Kong and the region by drawing on the great cultural traditions of China and the West. In recent years the University has emerged as a major research institution with nine faculties, a School of Business and more than 100 departments and subdivisions of studies and learning. There is currently an enrolment of more than 15,000 students, full-time and part-time, of which 4,000 are at post-graduate level. Overseas students from more than 40 countries are attracted to HKU to pursue the research degrees of $\mathrm{PhD}$ and MPhil. English is the language of instruction at HKU.

Our firm commitment to research excellence and internationalisation has established the University as one of the top research universities in the Region. We are committed to our vision of globalisation and enhancing our research excellence.

\section{Professor: Chair of Anaesthesiology}

Applications are invited for appointment as Professor: Chair of Anaesthesiology (Ref: RF97/98-97) tenable from 1 September 1999. Appointment will initially be made on a three-year fixed-term basis, with a possibility of renewal.

All staff of the Department of Anaesthesiology have to teach undergraduate students within the curriculum of the Faculty of Medicine as well as to supervise postgraduates. In addition, they are required to provide clinical services and to engage in research.

Applicants should be medically qualified and should possess strong academic qualifications. Higher degrees and specialist qualifications are preferred. They should have a substantial research and publications record.

The University reserves the right not to fill the post or to fill the post by invitation or to make an appointment at a lower level.

Annual salary (attracting 15\% (taxable) terminal gratuity] will be within the professorial range, which is not less than HK\$1.5M (approx C $\$ 297,507$; Canadian dollar equivalent as at 27 October 1998) with starting salary depending on qualifications and experience. At current rates, salaries tax will not exceed $15 \%$ of gross income. Leave, medical/dental benefits, and a monthly cash allowance of not less than $\mathrm{HK} \$ 62,081$ will be offered to the successful candidate

Further particulars and application forms can be obtained on WWW at http://www.hku.hk/apptunit/ or from the Appointments Unit, Registry, The University of Hong Kong, Hong Kong (Fax (852) 25406735 or 25592058 ; E-mail: apptunit@reg.hku.hk). Closes 31 January 1999.

The University is an equal opportunity employer and is working towards a smoke-free environment

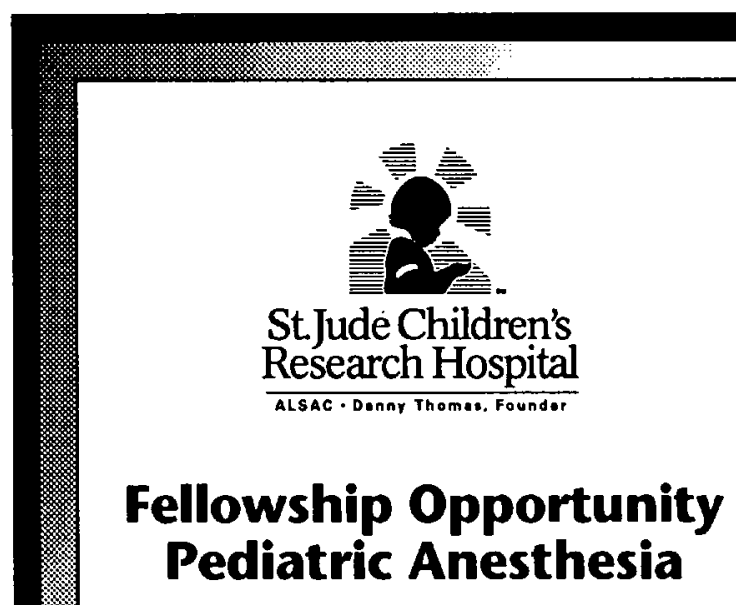

The Division of Anesthesia at St. Jude Children's Research Hospital is accepting applications for a Pediatric Anesthesia Fellowship position. Eligible candidates will have completed an anesthesia residency program. The successful applicant will be trained in all areas of pediatric anesthesia care and pain management. The fellowship program will be tailored to the needs of the candidate, but will include clinical training in the care of children with a variety of childhood malignancies as well as experience in clinical and basic research. The fellowship will be for one year with an option to gain additional laboratory or clinical research experience. The fellowship year will be divided half-time at St. Jude Children's Research Hospital, an institution with a pediatric cancer surgical load of 5,000 cases per year and half-time at the LeBonheur Children's Medical Center, where 10,000 cases per year are performed and where all pediatric surgical specialties are represented.

Qualified candidates should send a completed application [for application materials, please visit our website (www,stiude.org) see Research and Science: Education and Training], a curriculum vitae, a brief description of research interests and three letters of reference to the address below.

\section{Pediatric Anesthesiologist}

The Division of Anesthesia is also inviting qualified applicants to apply for the full-time position of Staff Pediatric Anesthesiologist. Applicants should be board eligible or board certified in anesthesiology and should have completed a fellowship in Pediatric Anesthesiology. The hospital offers experience in all aspects of pediatric anesthesia and pediatric pain management. Interested individuals should submit a letter of application and send curriculum vitae to:

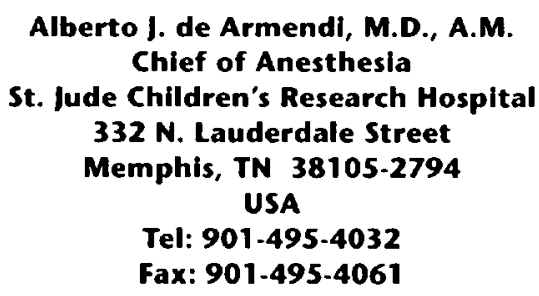

